\title{
Erratum to: Circadian Rhythm Disturbances Due to Exposure to Acidified Conditions and Different Photoperiods in Juvenile Olive Flounder (Paralichthys olivaceus)
}

\author{
Dae-Won Lee ${ }^{1,2} \cdot$ Jin Ah Song ${ }^{2} \cdot$ Heung-Sik Park ${ }^{1} \cdot$ Cheol Young Choi ${ }^{2}$
}

Published online: 31 May 2021

○ Korea Institute of Ocean Science \& Technology (KIOST) and the Korean Society of Oceanography (KSO) and Springer Nature B.V. 2021

\section{Erratum to: Ocean Science Journal \\ https://doi.org/10.1007/s12601-021-00018-y}

Due to an unfortunate oversight the author order and their affiliations have been given erroneously. It should read:

Dae-Won Lee ${ }^{1,2} \cdot$ Jin Ah Song ${ }^{2} \cdot$ Heung-Sik Park ${ }^{1} \cdot$ Cheol Young $\mathrm{Choi}^{2}$.

The original article has been corrected.

Publisher's Note Springer Nature remains neutral with regard to jurisdictional claims in published maps and institutional affiliations.

The original article can be found online at https://doi.org/10.1007/ s12601-021-00018-y.

Cheol Young Choi

choic@kmou.ac.kr

1 Marine Bio-Resources Research Unit, Korea Institute of Ocean Science and Technology, Busan 49111, Republic of Korea

2 Division of Marine BioScience, National Korea Maritime and Ocean University, Busan 49112, Republic of Korea 